\title{
DO THE MAXIMA OF AIR POLLUTANTS COINCIDE WITH THE INCIDENCE OF CHILDHOOD ASTHMA EXACERBATIONS IN ATHENS, GREECE?
}

\author{
P.T. NASTOS ${ }^{1, *}$ \\ A.G. PALIATSOS ${ }^{2}$ \\ K.N. PRIFTIS ${ }^{3}$
}

\author{
${ }^{1}$ Laboratory of Climatology and Atmospheric Environment \\ Faculty of Geology and Geoenvironment \\ University of Athens, Panepistimioupolis \\ 15784 Athens, Greece \\ ${ }^{2}$ General Department of Mathematics \\ Technological and Education Institute of Piraeus \\ 250 Thivon and P. Ralli Str., 12244 Athens, Greece
}

*to whom all correspondence should be addressed: e-mail: nastos@geol.uoa.gr

\begin{abstract}
In the present study an assessment of the influence of the ambient air pollution on the incidence of the Childhood Asthma Admissions (CAA) is attempted by using cross spectrum analysis. The medical data concern the hospital registries of the three main Children's Hospitals of Athens for the 14-year period, 1987-2000. The air pollution data used in this study were mean monthly concentrations of $\mathrm{CO}$, Black Smoke (BS), $\mathrm{NO}_{\mathrm{x}}, \mathrm{SO}_{2}$, and $\mathrm{O}_{3}$, averaged over all the available stations, for each air pollutant, in the network of the Greek Ministry of the Environment, Physical Planning and Public Works (GMEPPPW) for the aforementioned 14-year period. The performed analysis revealed that a pronounced seasonal variation of asthma exacerbation among Athenian children does exist, rising during the cold damp period in pre-schoolers and peaking around May in the schoolchildren. We found that asthma admissions are associated with ambient air pollution at different frequencies. Asthma exacerbation among the first age group (0-4 years) is strongly depended on winter air pollution whereas older children (5-14 years) appear to be more vulnerable to the exposure of primary air pollutants mainly during late spring. Our findings strengthen the aspect that weather conditions such as sea breeze, mainly happen at the late spring or early summer in association with air pollution episodes could affect childhood asthma exacerbation.
\end{abstract}

KEYWORDS: Childhood asthma admissions, ambient air pollution, cross spectrum analysis, Athens.

\section{INTRODUCTION}

Asthma is characterized by inflammation of the airways with intermittent bronchospasm, which is caused by the inflammation of the mucosa surrounding the air passageways. The inflammation makes the airways smaller and therefore making it more difficult for air to move in and out of the lung. According to the American Academy of Allergy Asthma \& Immunology, asthma is, unfortunately, all too common. In fact, asthma is the most common chronic disorder in children and adolescents, affecting nearly five million children under the age of 18 , including an estimated 1.3 million children under the age of five. Fifty to $80 \%$ of children affected with asthma develop symptoms before they are five years old. Among the factors which trigger asthma, ambient air pollution and weather variability are of great importance. Several recent studies have reported associations between ambient pollutants and Childhood Asthma Admissions (CAA) (Jaffe et al., 2003; Trasande and Thurston, 2005; Paliatsos et al., 2006). During winter a rise of $100 \mathrm{\mu g} \mathrm{m}^{-3}$ in $\mathrm{SO}_{2}$ might result in four more asthma admissions each day, for residents of Birmingham (Walters et al., 1994) while a 35\% increased likehood of an asthma emergency department visit per $50 \mu \mathrm{g} \mathrm{m}^{-3}$ increase in $\mathrm{SO}_{2}$ in Cincinnati (Jaffe et al., 2003). On the contrary, many researchers did not find any significant associations 
between ambient ozone concentrations and CAA (Ostro et al., 1999; Jalaludin et al., 2004; Paliatsos et al., 2006).

In this study, we examine the possible relationship between childhood asthma admissions and ambient air pollution in different frequencies, using spectrum analysis. Moreover, we make an effort to interpret the air pollutant's harmonics extracted, revealing the environmental procedures responsible for childhood asthma exacerbations in greater Athens area.

\section{DATA AND METHODS}

The CAA used, in this analysis were recorded and filed by the hospital registries of the three main Children's Hospitals of Athens for the 1987-2000 period, covering approximately 78$80 \%$ of the paediatric beds of metropolitan area of Athens. All children admitted with the diagnosis of "asthma", "asthmatic bronchitis" or "wheezy bronchitis", aged 0-14 years, living in the above-mentioned region was included. They were classified into two age groups: 0-4 and 5-14 years. Monthly CAA rates, after adjusting for paediatric beds that are not accounted for (approximately $20-22 \%$ of total number), were expressed per $10^{5}$ populations aged the same as the studied groups. The estimation of the population for each year of the study period was based upon the 1981 and 1991 national census. On the other hand, the air pollution data used were mean monthly concentrations of $\mathrm{CO}, \mathrm{BS}, \mathrm{NO}_{\mathrm{x}}, \mathrm{SO}_{2}$, and $\mathrm{O}_{3}$, averaged over all the available stations, for each air pollutant, in the network of the GMEPPPW for the 14-year period, 1987-2000.

For the harmonic analysis of the annual variation of the CAA and the concentrations of the aforementioned ambient air pollutants, using mean monthly values, the following formula, which is the most common for environmental research, is applied (Conrad and Pollak, 1950):

$$
\mathrm{y}=\alpha_{0}+\alpha_{1} \sin \left(\frac{2 \pi t}{12}+\phi_{1}\right)+\alpha_{2} \sin \left(\frac{2(2 \pi \mathrm{t})}{12}+\phi_{2}\right)+\ldots+\alpha_{\kappa} \sin \left(\frac{\mathrm{k}(2 \pi \mathrm{t})}{12}+\phi_{\mathrm{k}}\right)+\ldots
$$

where $\alpha_{0}$ is the arithmetic mean of the mean monthly values, $\alpha_{1}, \alpha_{2}, \ldots, \alpha_{k}$ are the amplitudes and $\varphi_{1}, \varphi_{2}, \ldots, \varphi_{\mathrm{k}}$ are the phase angles of the respective harmonic terms with $\mathrm{k}=1,2,3, \ldots$ Another form of the same formula is the following:

$$
\mathrm{y}=\mathrm{a}_{0}+\sum_{\mathrm{k}=1}^{\mathrm{n}} \mathrm{a}_{\mathrm{k}} \sin \left(\frac{2 \mathrm{k} \pi \mathrm{t}}{12}+\phi_{\mathrm{k}}\right)
$$

In the process, the time of maximum for CAA and ambient air pollutants is evaluated, using the formula:

$$
\mathrm{t}_{\max }=\left(\frac{\pi}{2}-\phi_{\mathrm{k}}\right) \frac{12}{2 \mathrm{k} \pi}
$$

The second step of the performed analysis is the application of cross spectrum analysis to CAA and air pollutants concentrations time-series. The purpose of cross-spectrum analysis is to detect the correlations between two series at different frequencies. The estimated crossamplitude can be interpreted as a measure of covariance between the respective frequency components in the two series. One can standardize the cross-amplitude values by squaring them and dividing by the product of the spectrum density estimates for each series. The result is called the squared coherency, which can be interpreted similar to the squared correlation coefficient that is, the coherency value is the squared correlation between the cyclical components in the two series at the respective frequency. However, the coherency values should not be interpreted by themselves; for example, when the spectral density estimates in both series are very small, large coherency values may result (the divisor in the computation of the coherency values will be very small), even though there are no strong cyclical components in either series at the respective frequencies. Finally, the phase shift estimates (usually denoted by the Greek letter $\psi$ ) are measures of the extent to which each frequency component of one series leads or lag the other. 


\section{RESULTS AND DISCUSSION}

The annual variation of the CAA regarding the pre-school children 0-4 years old is well described by three harmonic terms, which explain $90 \%$ of the total variance (Table 1). The first harmonic accounts for $69.8 \%$ of the explained variance, while the second for $11.1 \%$ and the third for $9.5 \%$. On the other hand, the annual variation of the CAA for the older children 5 14 years old is also well described by three harmonic components, explaining $80 \%$ of the total variance. In this point, we have to mention that the second harmonic interpret $44.5 \%$ of the total variance and follows the third with $31.2 \%$ and the first with $4.3 \%$. Figure 1 depicts the annual variation of the amplitude of CAA harmonics for each examined children age group.

Table 1. Fourier results with respect to CAA for the two age groups, $\left(a_{1}, a_{2}, a_{3}\right.$ : the amplitudes of the first, second and third harmonic term and $t_{1}, t_{2}, t_{3}$ : the time of maximum for the first, second and third harmonic term, respectively)

\begin{tabular}{cccccccccc}
\hline CAA & $\mathbf{a}_{\mathbf{1}}$ & $\mathbf{t}_{\mathbf{1}}$ & $\mathbf{\%}$ & $\mathbf{a}_{\mathbf{2}}$ & $\mathbf{t}_{\mathbf{2}}$ & $\mathbf{\%}$ & $\mathbf{a}_{\mathbf{3}}$ & $\mathbf{t}_{\mathbf{3}}$ & $\%$ \\
\hline (0-4 years) & 22.0 & 26 December & 69.8 & 8.8 & 29 April & 11.1 & 8.1 & 26 January & 9.5 \\
\hline (5-14years) & 0.8 & 23 February & 4.3 & 2.4 & 17 May & 44.5 & 2.0 & 22 January & 31.2 \\
\hline
\end{tabular}

With regard to the air pollutant's concentrations, the annual variation is well defined by two harmonic terms, explaining more than $96 \%$ of the total variance (Figure 2). The percentage of the total variance explained by the first harmonic is high enough (greater than $81 \%$ ) for all air pollutants examined, so that the variation of the first harmonic is quite similar to the annual variation of the original data. The second harmonic interprets less of the ambient air pollution variability in the greater Athens area (Table 2).
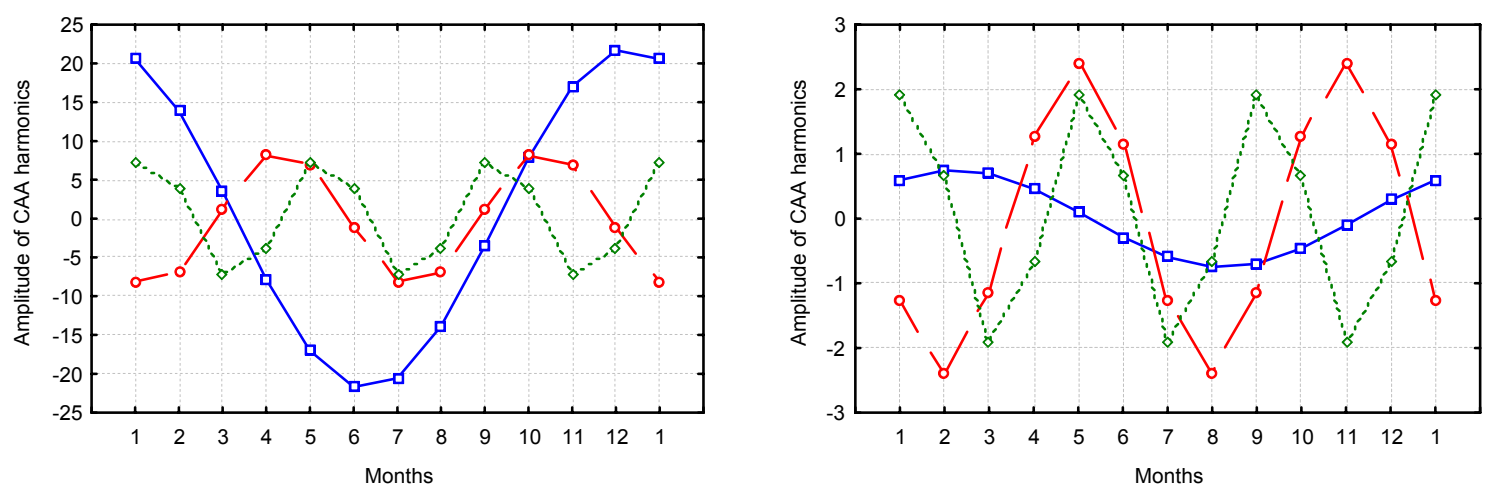

Figure 1. Annual variation of the amplitude of CAA harmonics (solid line for first harmonic, dash line for second harmonic, dot line for third harmonic) for pre-school children 0-4 years old (left panel) and older children 5-14 years old (right panel)

Further to, the time of maximum for CAA and air pollutant's concentrations is evaluated, for each harmonic component, and is presented in Tables 1,2. The maximum of the first harmonic for CAA (aged 0-4 years) is appeared in the late December, while the maximum of the second and third harmonic occurs at the end of April (October) and the end of January (May and September), respectively. Concerning CAA for older children, the maximum of the dominant second harmonic occurs in the middle of May (November), while secondary peaks are exhibited at the end of January (May and September), and end of February for the third and first harmonic, respectively. 
Table 2. Fourier results with respect to ambient air pollutants, $\left(a_{1}, a_{2}\right.$ : the amplitudes of the first and second harmonic term and $t_{1}, t_{2}$ : the time of maximum for the first and second harmonic term, respectively)

\begin{tabular}{lrrrrrr}
\hline $\begin{array}{l}\text { Ambient air } \\
\text { pollutants }\end{array}$ & \multicolumn{1}{c}{$\mathbf{a}_{\mathbf{1}}$} & \multicolumn{1}{c}{$\mathbf{t}_{\mathbf{1}}$} & \multicolumn{1}{c}{$\%$} & \multicolumn{1}{c}{$\mathbf{a}_{\mathbf{2}}$} & \multicolumn{1}{c}{$\mathbf{t}_{\mathbf{2}}$} & \multicolumn{1}{c}{$\%$} \\
\hline $\mathbf{C O}\left(\mathrm{mg} \mathrm{m}^{-3}\right)$ & 0.8 & 25 December & 89.7 & 0.26 & 4 June & 8.8 \\
\hline $\mathbf{B S}\left(\boldsymbol{\mu \mathbf { g ~ m } ^ { - 3 } )}\right.$ & 15.3 & 25 December & 88.7 & 5.1 & 18 June & 9.8 \\
\hline $\mathrm{NO}_{\mathbf{x}}\left(\boldsymbol{\mu \mathbf { g ~ m } ^ { - 3 } )}\right.$ & 31.7 & 16 January & 82.3 & 13.4 & 31 May & 14.8 \\
\hline $\mathrm{SO}_{\mathbf{2}}\left(\boldsymbol{\mu \mathrm { g } \mathrm { m } ^ { - 3 } )}\right.$ & 11.0 & 24 January & 81.1 & 4.8 & 9 July & 15.1 \\
\hline $\mathbf{O}_{\mathbf{3}}\left(\boldsymbol{\mu \mathbf { g ~ m } ^ { - 3 } )}\right.$ & 24.6 & 5 July & 95.8 & 4.6 & 13 February & 3.4 \\
\hline
\end{tabular}

The seasonal variation of CAA in Athens has already been reported, rising during the cold damp period in the 0-4 year age group, but peaking around May in the 5-14 year age group (Priftis et al., 1993). This pattern of distribution is also similar to the seasonality of asthma admissions in Malta (Grech et al., 2002), and Ankara, Turkey (Berktas and Bircan, 2003), where the first asthma visits peak is related to allergic pollens during April and the second peak probably is due to opening of schools during September-October. Another study examining the seasonal patterns of asthma hospitalizations in relation to age and gender in Ontario, Canada, for a period of 12 years, revealed that there is a strong evidence of an autumn peak and summer trough seasonal pattern for asthma hospitalizations (Crighton et al., 2001).

The time of maximum of the fist harmonic for the $\mathrm{CO}$ and $\mathrm{BS}$ concentrations is apparent at the end of December, for $\mathrm{NO}_{\mathrm{x}}$ and $\mathrm{SO}_{2}$ concentrations at the middle and end of January, respectively and for $\mathrm{O}_{3}$ at the beginning of July. Concerning the second harmonics, the time of maximum for the $\mathrm{CO}$ and $\mathrm{NO}_{\mathrm{x}}$ concentrations is exhibited at the beginning of June (December) or the end of May (November), respectively, for BS at the middle of June (December), for $\mathrm{SO}_{2}$ at the beginning of July (January) and for $\mathrm{O}_{3}$ at the middle of February (August).

In the process, in order to find out the coherence between CAA and ambient air pollution we applied the cross spectrum analysis to the CAA and air pollutants concentrations time-series. The purpose of cross-spectrum analysis is to detect the correlations between two series at different frequencies. Taking into account the cross amplitudes and the squared coherencies extracted we can conclude that CAA of younger age group are strongly correlated with the examined air pollutants concentrations at twelve months period, while small correlations are appeared at six months period with a lag of quassi two months period (according to phase spectrum). On the other hand, CAA of older children are mainly correlated with the air pollutants concentrations at six months period and secondary at twelve months period. This denotes that the air pollution episodes existed at the late spring or early summer exacerbates CAA with regard to older children. Figure 3 depicts the cross amplitude for ambient air pollutants and CAA for the pre-school children, where dominant peak at twelve months is revealed and moreover, for the older children, where two strong peaks at twelve and six months appear clearly. The six months peak concerning the older children is higher than the respective one of twelve months with respect to $\mathrm{BS}, \mathrm{NO}_{\mathrm{x}}$ and $\mathrm{SO}_{2}$, while it is less in the case of $\mathrm{O}_{3}$ and almost equal in the case of $\mathrm{CO}$. Besides, the four months peaks appeared are of less importance, with an exception in the case of $\mathrm{SO}_{2}$, where the amplitude of the four months peak is a quarter the amplitude of the dominant six month peak, revealing that there is a moderate relationship between $\mathrm{CAA}$ and $\mathrm{SO}_{2}$ in September, which coincides with the opening of schools. 

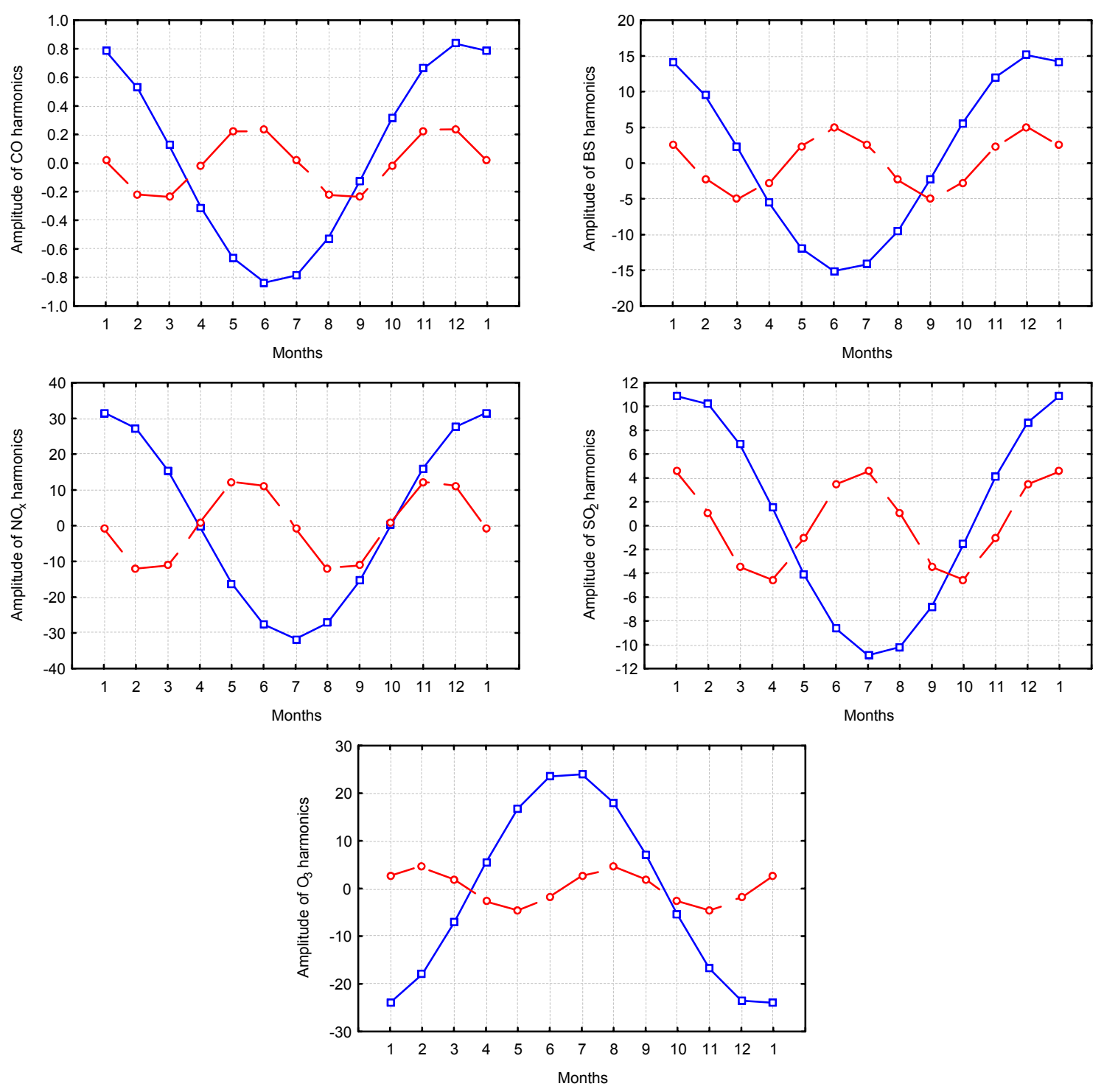

Figure 2. Annual variation of the amplitude of ambient air pollutants harmonics (solid line for first harmonic, dash line for second harmonic)

A physical explanation of the above findings is that probably, the first harmonic component concerns the anthropogenic factor (the heavy car traffic), while the second one the meteorological factor (the development of the sea breeze and the northeastern flow of the "Etesians" winds). More particularly, the time of the occurrence of maximum concentrations for primary air pollutants during December and January is mainly due to central heating and road traffic while the summer minimum is due to reduced private car traffic, because of JulyAugust vacations but is also enhanced by the blow of the "Etesians" winds. On the other hand, the oxidation of $\mathrm{NO}_{x}$ to produce $\mathrm{O}_{3}$ under sunshine conditions is appeared mainly in summer time, and this is the reason of the maximum peak of $\mathrm{O}_{3}$. The fact that no asthma exacerbations occurred at the beginning of July when the time of maximum of the fist harmonic for the $\mathrm{O}_{3}$ should be due to the summer holidays when most of the children's population of Athens live out of the city.

The cross spectrum analysis for younger children shows the strong relationship between CAA and ambient air pollution during winter time. A possible interpretation is that the immune system of these pre-school children show a type of hyper-reactivity related to the frequent viral infections developed during the cold period of the year. In this case, increase ambient air pollution exacerbates CAA, and this is in agreement with the findings of other researchers. 

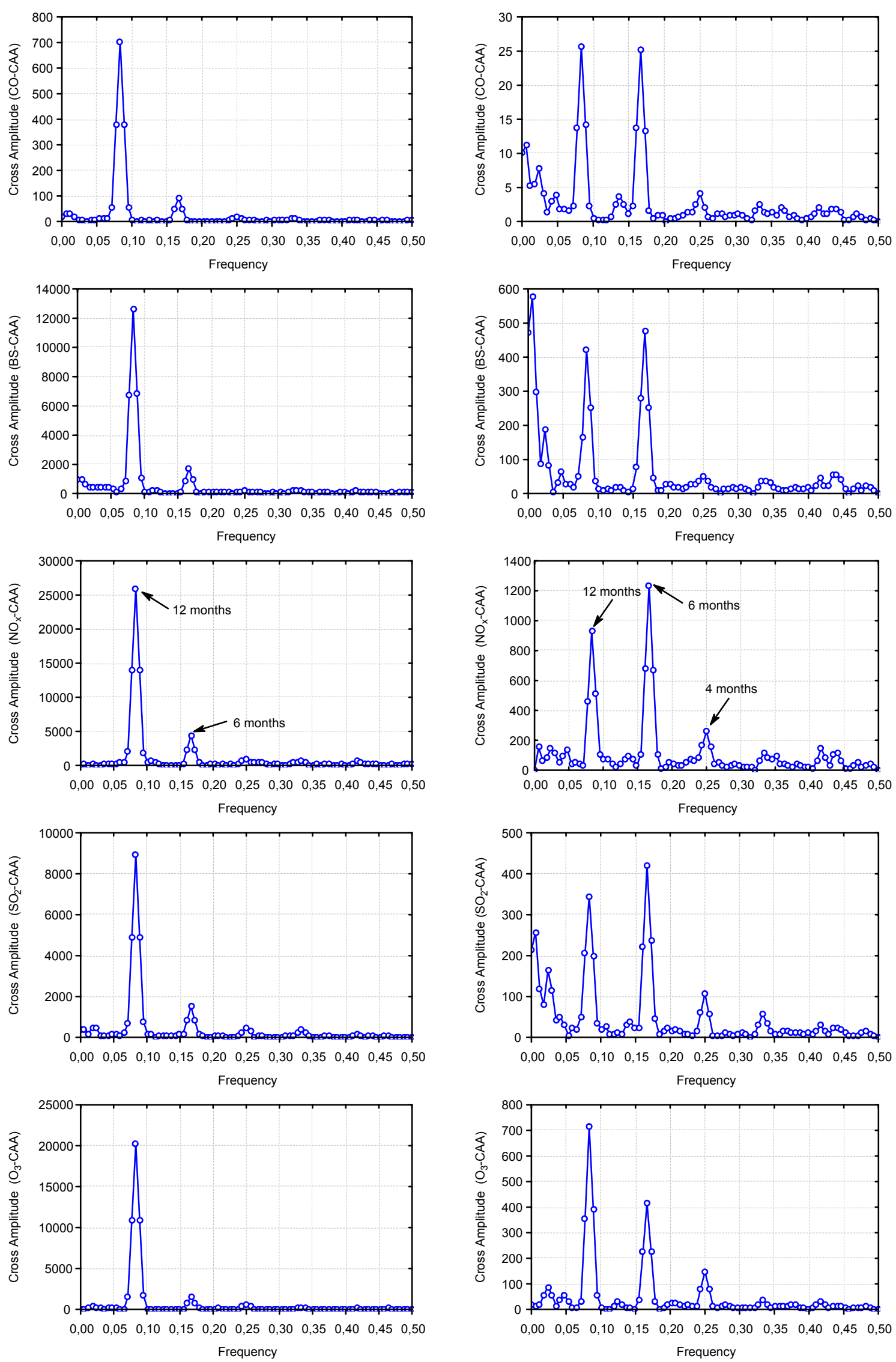

Figure 3. Cross amplitude for ambient air pollutants and CAA for pre school children 0-4 years old (left panel) and older children 5-14 years old (right panel) 
The major factors associated with emergency room visits of asthmatic children were high $\mathrm{NO}_{x}$, high $\mathrm{SO}_{2}$, and high atmospheric pressure while negative correlation between the visits of asthmatic children and ozone concentrations (Garty et al., 1998), whereas there were no associations between ambient ozone concentrations and respiratory symptoms, asthma medication use, and doctor visits for asthma in a cohort of Australian children (Jalaludin et al., 2004). Studies in Santa Clara, California, $\mathrm{NO}_{2}$ levels were associated with childhood asthma exacerbations (Lipsett et al., 1997), while a strong association between the short term effect of winter air pollution (mainly due to $\mathrm{SO}_{2}$ ) and the health of asthmatic children in Paris is well documented (Segala et al., 1998).

The air pollution episodes appear in Athens, during all the seasons of the year, but the maximum is strongly associated with the development of sea breeze (Kallos et al., 1993). Except the great frequency of sea breeze, the main factors that form air pollution episodes are the local topography with mountains surrounding the basin of Athens and preventing the ventilation of the urban area, the wind flow field, which in the boundary layer is mainly of northeastern direction during the warm period of the year and the existing sunshine. The last factor is responsible for the transformation of primary pollutants such as nitrogen oxides to photochemical pollutants. The maximum appeared in late spring or early summer should be due to sea breeze, which is more often for that period of the year. It is well known that the circulation of sea breeze is appeared during warm days with weak pressure patterns. The sea breeze tends to stratify the atmosphere above the city, with the result of temperature inversion that traps the pollutants near the ground. Increased air stagnation was shown to be a surrogate for accumulation of the products of incomplete combustion, including carbon monoxide and fine particulate levels of organic and elemental carbon, and was strongly associated with asthma aggravation (Norris et al., 2000).

The main limitation of this study was that admission rates were given on a monthly basis and not weekly or daily. In that way, any short-term effect of short duration of air pollutants could be lost, but not of changes for longer duration. The very prolonged study period (13 years) eliminates that weakness and allows possible detection of repeated specific weather conditions affecting asthma symptoms. Monthly changes have already been used as a reliable tool in the literature (Priftis et al., 1993, Grech et al., 2002, Paliatsos et al., 2006).

\section{CONCLUSIONS}

In conclusion, our results reveal that Childhood Asthma Admissions in Athens, Greece, are associated with ambient air pollution at different frequencies. Asthma exacerbation in children of the first age group (0-4 years) is strongly depended on winter air pollution, which is interpreted by the first harmonic component accounting for more than $96 \%$ of the total variance of the primary ambient air pollutants. On the other hand, older children (5-14 years) seem to be more vulnerable to the exposure of primary air pollutants mainly during late spring. Spring ambient air pollution is explained by the second harmonic component, which, notwithstanding interprets less of the total variance, in relation to the prevailing meteorological conditions, such as sea breeze, tend to maximize the pollutant's concentrations in the greater Athens area and affect the health of asthmatic children.

\section{REFERENCES}

Berktas, B.M. and Bircan, A. (2003), Effects of atmospheric sulphur dioxide and particulate matter concentrations on emergency room admissions due to asthma in Ankara, Tuberk Toraks, 51, 231-238.

Conrad V. and Pollak L.W. (1950), Methods in Climatology, Harvard University Press, Cambridge, Massachusetts.

Crighton, E.J., Mamdani, M.M. and Upshur, R.E.G. (2001), A population based time series analysis of asthma hospitalizations in Ontario, Canada: 1988 to 2000, BMC Health Services Research, 1, 7.

Garty, B.Z., Kosman, E., Ganor, E., Berger, V., Garty, L., Wietzen, T., Waisman, Y., Mimouni, M. and Waisel, Y. (1998), Emergency room visits of asthmatic children, to air pollution, weather, and relation airborne allergens, Annals of Allergy, Asthma and Immunology, 81, 563-570. 
Grech, V., Balzan, M., Asciak, R.P. and Buhagiar, A. (2002), Seasonal variations in hospital admissions for asthma in Malta, Journal of Asthma, 39, 263-268.

Jaffe, D.H., Singer, M.E. and Rimm, A.A. (2003), Air pollution and emergency department visits for asthma among Ohio Medicaid recipients, 1991-1996, Environmental Research, 91, 21-28.

Jalaludin, B.B., O'Toole, B.I. and Leedor, S.R. (2004), Acute effects of urban ambient air pollution on respiratory symptoms, asthma medication use, and doctor visits for asthma in a cohort of Australian children, Environonmental Research, 95, 32-42.

Kallos, G., Kassomenos, P. and Pielke, R.A. (1993), Synoptic and mesoscale weather conditions during air pollution episodes in Athens, Greece, Boundary-Layer Meteorology, 62, 163-184.

Lipsett, M., Hurley, S. and Ostro, B. (1997), Air pollution and emergency room visits for asthma in Santa Clara County, California, Environmental Health Perspectives, 105, 216-222.

Norris, G., Larson, T., Koenig, J., Claiborn, C. and Sheppard, L. (2000), Asthma aggravation, combustion, and stagnant air, Thorax, 55, 466-470.

Ostro, B.D., Eskeland, G.S., Sanchez, J.M. and Feyzioglu, T. (1999), Air pollution and health effects: a study of medical visits among children in Santiago, Chile, Environmental Health Perspectives, 107, 69-73.

Paliatsos, A.G., Priftis, K.N., Ziomas, I.C., Panagiotopoulou-Gartagani, P., Tapratzi-Potamianou, P., Zachariadi-Xypolita, A., Nicolaidou, P. and Saxoni-Papageorgiou, P. (2006), Association between ambient air pollution and childhood asthma in Athens, Greece, Fresenius Environmental Bulletin, 15, 614-618.

Priftis, K., Anagnostakis, J., Harokopos, E., Orfanou, I., Petraki, M. and Saxoni-Papageorgiou, P. (1993), Time trends and seasonal variation in hospital admissions for childhood asthma in the Athens region of Greece: 1978-88, Thorax, 48, 1168-1169.

Trasande, L. and Thurston, G.D. (2005), The role of air pollution in asthma and other paediatric morbidities, Journal of Allergy and Clinical Immunology, 115, 689-699.

Walters, S., Griffiths, R.K. and Ayers, J.G. (1994), Temporal association between hospital admissions for asthma in Birmingham and ambient levels of sulphur dioxide and smoke, Thorax, 49, 133-140. 